\title{
KIVESVAARA C2 CHONDRITE: SILICATE PETROGRAPHY AND CHEMICAL COMPOSITION
}

\author{
KARI A. KINNUNEN and RISTO SAIKKONEN
}

\begin{abstract}
KINNUNEN, KARI A. and SAIKKONEN, RISTO, 1983: Kivesvaara C2 chondrite: silicate petrography and chemical composition. Bull. Geol. Soc. Finland 55, 1. 35-49.

Fragments of the Kivesvaara meteorite were said to have been found in Paltamo, northern Finland in 1968. The chemical and mineral composition and the textural features show that this meteorite is a rare $\mathrm{C} 2$ carbonaceous chondrite. The research material consists of two fragments with traces of fusion crust (total weight $164 \mathrm{~g}$ ). The meteorite is composed of a fine-grained phyllosilicate matrix $(77.5 \mathrm{vol} . \%)$ and of clasts: amoeboid olivine aggregates and finegrained Ca-Al-Ti-rich aggregates (CAI inclusions), fluid drop chondrules and polymineralic fragments, monomineralic grains and fragments mainly of olivine, and opaque minerals. The clasts define a weak planar orientation and most of them are surrounded by black matrix rinds. The chemical composition of the Kivesvaara meteorite closely resembles Murchison C2 chondrite.
\end{abstract}

Key words: meteorite, carbonaceous chondrite, chemical composition, textural modal composition, grain size distribution, CAI inclusions, matrix textures, chondrule textures, euhedral olivine, melt inclusions, Finland.

Kari A. Kinnunen and Risto Saikkonen: Geological Survey of Finland, Kivimiehentie 1, SF-02150 Espoo 15, Finland.

\section{Introduction}

In May 1968 blackish stones with a strange bituminous odour were said to have been encountered by Mr Pertti Huusko and six other men while planting trees on the eastern side of Kivesvaara, a hill in Paltamo commune, northern Finland (lat. $=64^{\circ} 27^{\prime}$, long. $=27^{\circ} 34^{\prime}$ ). Unfortunately, it was not until October 1980 that the stones were identified as a carbonaceous chondrite. Despite a systematic search in 1981 the two fragments with a total weight of $164 \mathrm{~g}$ remain the only samples. Field observations and interviews with local people suggested that the meteorite had fallen during winter 1968. The Kivesvaara meteorite is displayed in the meteorite collection at the Mineralogical Museum of the University of Helsinki. In this paper we describe its textural features and give its chemical composition as established by wetchemical methods. 


\section{Carbonaceous chondrites}

Chondritic meteorites are the oldest known rock samples (age 4.4-4.6 GY) from our solar system. They most probably derive from asteroids, which may represent extinguished comets or small asteroids, or both. The chondritic meteorites are our only samples of the early years of the solar system, and they seem to provide frozen evidence of incipient planet-building processes.

Because of their weakly metamorphosed nature, the carbonaceous chondrites are crucial to meteorite research. Since the pioneering work of Wiik (1956), the carbonaceous chondrites have been studied intensively mainly in connection with space programmes. The reader is referred to Mason (1971), Nagy (1975), Kallemeyn and Wasson (1981), Dodd (1981) and Smith (1982) for detailed references and a summary. The current view interprets the carbonaceous chondrites as agglomeratic rocks that represent the outer regolithic layers of their parent bodies. There is compelling evidence that these bodies formed at the same time and from the same cosmoclastic material (interstellar grains and supernova debris) as the solar nebulae. Later collisions finally sent fragments of the bodies into earth-intersecting orbits.

Exhaustive studies on the carbonaceous chondrites have revealed many unexpected features of their chemical composition and petrological history. One peculiarity is their low-temperature phyllosilicate matrix with its content of organic compounds and water. On the other hand embedded in this matrix material there are high-temperature olivine and pyroxene clasts: chondrules, unmelted aggregates and single crystals and crystal fragments. The date when these high temperature clasts were condensed from solar nebulae or crystallized from a melt and the date when they accreted onto the parent bodies (the matrix age) may be separated by a considerable span of time, perhaps about $100 \mathrm{My}$ (see Macdougall and Kothari 1976). Likewise the isotopic anomalies in some Ca-Al-Ti-rich fine-grained clasts (CAI inclusions) strongly suggest that these clasts may have acquired some of their material from outside the solar system (see Scott 1982).

The research material of carbonaceous chondrites, however, is limited, only 20 chondrites classified in the $\mathrm{C} 2$ group being known (Table 1).

\section{Macroscopic description}

The Kivesvaara meteorite find consists of two fragments (Figs. 1 and 2). The larger fragment weighs $114 \mathrm{~g}$ with dimensions $6 \times 5 \times 4 \mathrm{~cm}$, and the smaller $50 \mathrm{~g}$ with dimensions $4 \times 2 \times 2 \mathrm{~cm}$. Part of the smaller fragment was used for the chemical analysis

Table 1. List of C2 chondrites.

\begin{tabular}{|c|c|c|}
\hline Name & Recovery & Reference \\
\hline Allan Hills 77306 & Find & Moore (1982) \\
\hline Allan Hills 78261 & Find & Moore (1982) \\
\hline Boriskino & Fall & Wasson (1974) \\
\hline Cochabamba & Find & $\begin{array}{l}\text { Kurat and Kracher } \\
\text { (1975) }\end{array}$ \\
\hline Cold Bokkeveld & Fall & Wasson (1974) \\
\hline Crescent & Fall & Wasson (1974) \\
\hline Erakot & Fall & Wasson (1974) \\
\hline Essebi & Fall & Wasson (1974) \\
\hline Haripura & Fall & Wasson (1974) \\
\hline Mighei & Fall & Wasson (1974) \\
\hline Murchison & Fall & Fuchs et al. (1973) \\
\hline Murray & Fall & Wasson (1974) \\
\hline Nawapali & Fall & Wasson (1974) \\
\hline Niger (I) & Find & Desnoyers (1980) \\
\hline Nogoya & Fall & Wasson (1974) \\
\hline Pollen & Fall & Wasson (1974) \\
\hline Santa Cruz & Fall & Wasson (1974) \\
\hline Yamato 74642 & Find & Moore (1982) \\
\hline Yamato 74662 & Find & Moore (1982) \\
\hline Yamato 75260 & Find & Moore (1982) \\
\hline
\end{tabular}



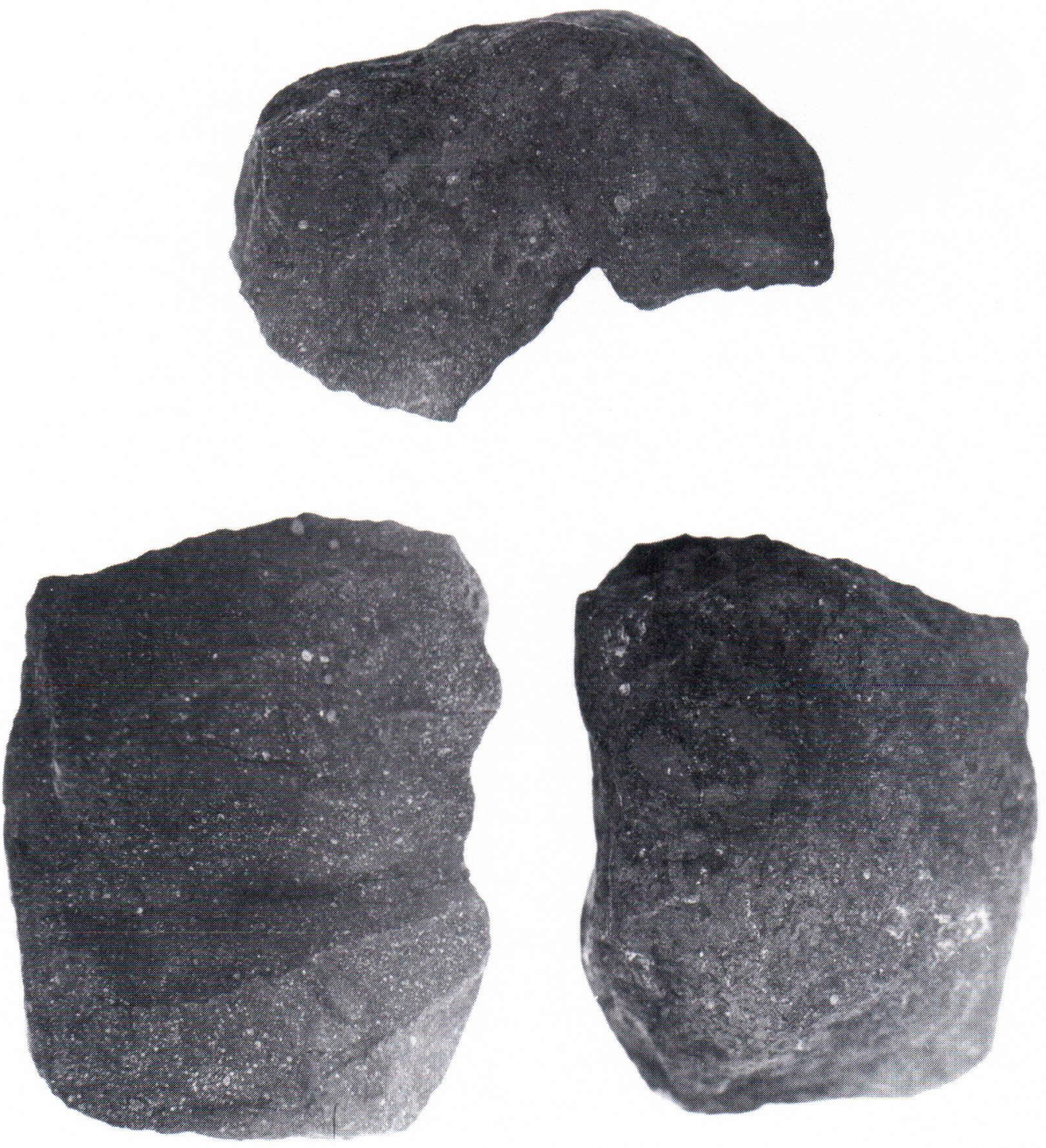

\section{$5 \mathrm{~cm}$}

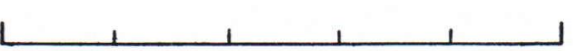

Fig. 1. The larger fragment of the Kivesvaara meteorite (114 g). Upper and lower right photographs: length and side view of the natural surface with patches of fusion crust. Lower left photograph: side view of the fresh fracture surface with light clasts in dark gray matrix material. Note the fracture planes revealing a joint system and the black areas devoid of larger clasts in the lower left photograph. 


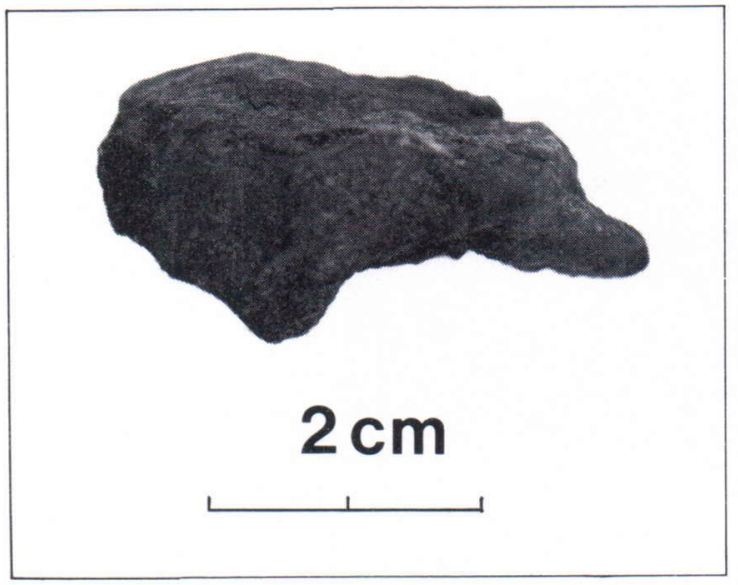

Fig. 2. The smaller fragment of the Kivesvaara meteorite $(50 \mathrm{~g})$

and for the thin and polished sections. Both meteorite fragments contain primary surfaces with patches of black and green scoriceaous glassy fusion crust and secondary fracture surfaces formed during the flight of the meteorite. The two fragments do not fit together.

The colour of the fresh fracture surfaces is dark olive green (colour code $5 \mathrm{Y} 3 / 1$ ). The bulk density of both samples ranged from 2.07 to 2.17 with the mean at $2.14 \mathrm{~g} / \mathrm{cm}^{3}$. The bulk density was determined by the conventional water immersion method and was found to increase with the increasing humidity of the sample. The magnetic properties of the Kivesvaara C2 chondrite will be reported elsewhere. The results (L. J. Pesonen, pers. comm., 1982) suggest the presence of a very strong and stable natural magnetization (NRM) and a moderate strong susceptibility.

Both meteorite fragments possess a weak planar orientation of their mineral grains and aggregates. A few black fragments of C1-like material lie parallel to the orientation. Normal to these planes are fractures that form one joint system.

\section{Petrographic description}

\section{Methods}

The textural composition was determined by point counting of a polished thin section in combined transmitted and reflected light. The criteria used for the identification of the textural components are essentially the same as in McSween (1979). The terminology used for the chondrule types is according to King and King (1978) and Gooding and Keil (1981). The grain sizes of the particles with maximum diameter over $0.1 \mathrm{~mm}$ were measured with an ocular screw micrometer in combined transmitted and reflected light. The matrix textures were observed from an ultrathin section (about $5 \mu \mathrm{m}$ ) in transmitted light.

\section{Textures}

The Kivesvaara meteorite is composed of fine-grained matrix and clasts in the form of amoeboid fine-grained mineral aggregates, chondrules, polymineralic broken fragments, monomineralic grains and fragments, and of opaque minerals (Table 2 and Fig. 3). A few black breccia fragments were noticed in ultra-thin section. The grain size frequency distribution curve for all particles with maximum diameter $\geq 100 \mu \mathrm{m}$ is within the limits reported by King and King (1978) for CM2 and CO3 meteorites (Fig. 4). There is a very close resemblance to the Pollen, Santa Cruz and Cold Bokkeveld C2 chondrites (cf. Table 1 in King and King 1978).

Most of the clasts are surrounded by black rinds composed of oriented matrix material devoid of larger clasts (Fig. 5). Some clasts lack rinds, some have broken rinds, and a few have loose rind fragments. This indicates that the rinds were formed, probably as layers of dust, before the accretion of the clasts. This is supported by the following petrographical features: 1) the rinds are stra- 


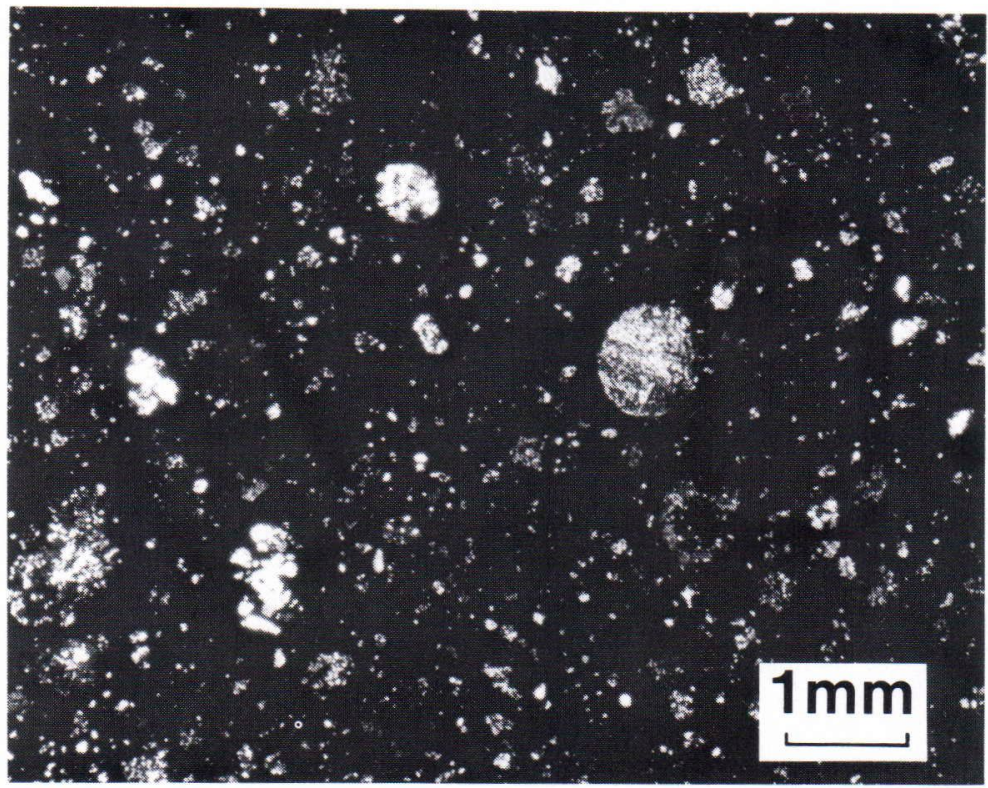

Fig. 3. Photomicrograph of the pronounced clastic texture of the Kivesvaara meteorite consisting of opaque matrix and clasts: fluid drop chondrules together with olivine and pyroxene aggregates and fragments. Transmitted, plane-polarized light.

tified (cf. McKay et al. 1970), 2) some rinds show a distinct microstratigraphy with altered metal spherules and microchondrules on the inner layer and with broken silicate fragments oriented along the bedding plane

Table 2. Textural modal analyses of Kivesvaara and twelve other $\mathrm{C} 2$ chondrites.

\begin{tabular}{lrc}
\hline Textural element & \multicolumn{2}{c}{ Volume percent } \\
\hline & $\begin{array}{l}\text { Kives- } \\
\text { vaara }\end{array}$ & $\begin{array}{l}\text { Range in } \\
\text { other C2 } \\
\text { chondrites }\end{array}$ \\
\hline $\begin{array}{l}\text { Matrix } \\
\text { Amoeboid olivine }\end{array}$ & 77.5 & $56.9-85.4$ \\
$\quad$ and Ca, Al-rich inclusions) & 8.3 & $0.9-11.5$ \\
$\begin{array}{c}\text { Chondrules and } \\
\text { polymineralic fragments }\end{array}$ & 8.2 & $5.1-16.1$ \\
$\begin{array}{c}\text { Monomineralic grains and } \\
\text { fragments (mostly olivine) }\end{array}$ & 4.7 & $4.4-21.2$ \\
\begin{tabular}{c} 
Opaque minerals \\
\hline
\end{tabular} & 0.3 & $0.6-3.0$ \\
\hline
\end{tabular}

Data on other C2 chondrites (Allan Hills 77306, Boriskino, Cold Bokkeveld, Crescent, Erakot, Essebi, Mighei, Murchison, Murray, Nogoya, Pollen, Santa Cruz) taken from McSween (1979, p. 1762, Table 1). in the outer layer, and 3) the rinds obliterate the surface irregularities of the original clast surface. Other explanations for the rind genesis may be diffusion halos in »impact-generated base surge or fall-back deposits» (Fig. 3

GRAIN SIZE IN MM.

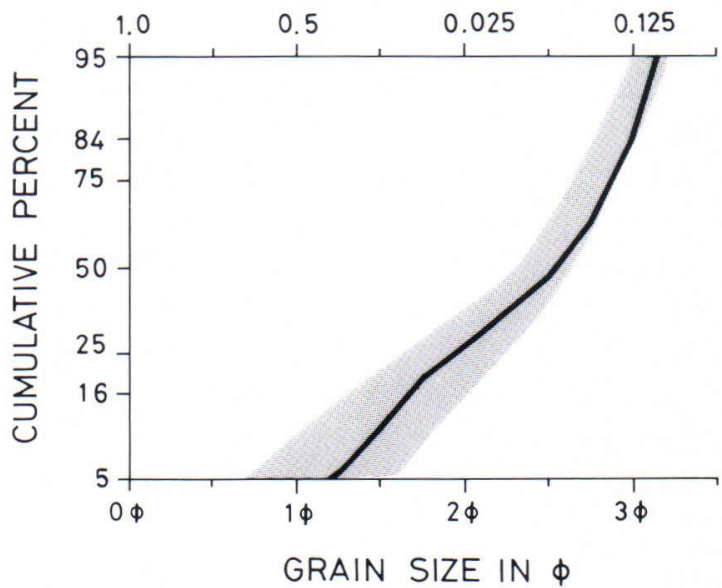

Fig. 4. The grain size frequency distribution curve for all particles $(\geq 100 \mu \mathrm{m})$ in Kivesvaara. The shaded area shows the limits of the size frequency curves for seven CM2 and five CO3 meteorites according to Fig 3 in King and King (1978). 


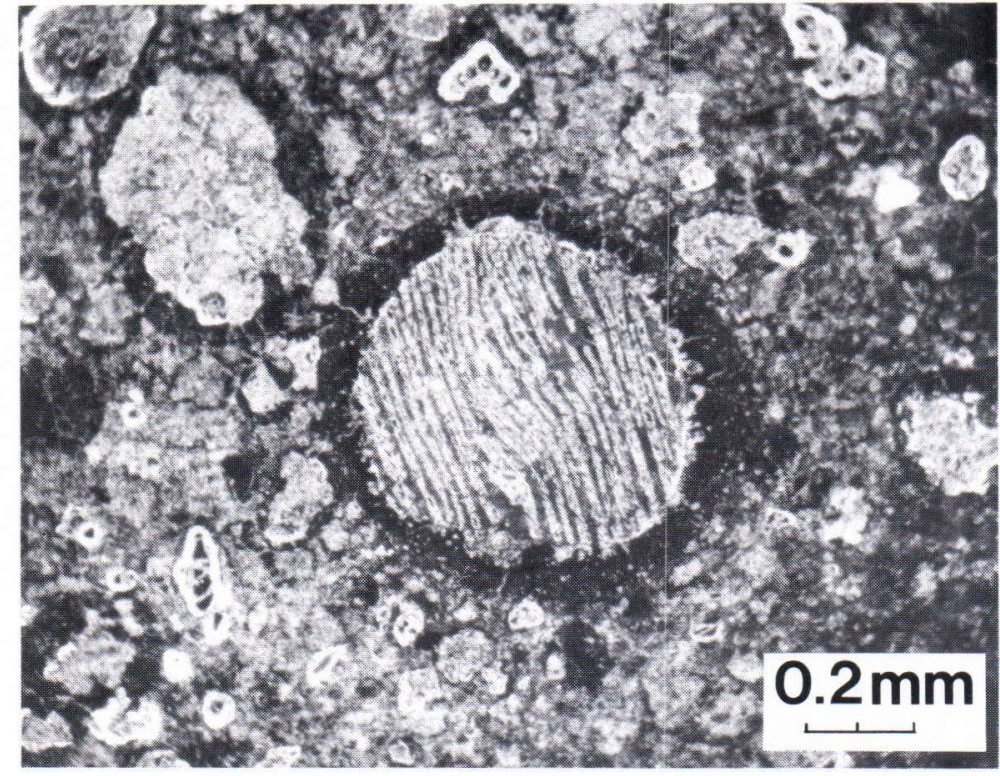

Fig. 5. Photomicrograph showing rinds surrounding one fluid drop chondrule and most of the aggregates. The monomineralic fragments are generally devoid of rind. The matrix is composed of altered aggregates surrounded by rinds. Dark-field unpolarized, reflected light. in King et al. 1972) or electrostatic aggregates (Alfvén and Arrhenius 1976, p. 180; Krinsley and Leach 1981). Allen et al. (1980) have studied the rinds surrounding chondrules in unequilibrated ordinary chondrites. They preferred the rind genesis in space by condensation or by accretion of fine particles on the chondrule surfaces.

The ultra-thin section reveals that the matrix contains remnants of altered xenolithic (?) clasts. One clast consists of a barred olivine chondrule, euhedral olivine and carbonate grains embedded in altered greenish material (glass?). This clast remnant is angular and its outlines cut the mineral grains and the chondrule. Most of the matrix clasts are without distinct textural properties (see Fig. 5) and may be interpreted as primary aggregates of interstellar dust. A few resemble altered microporphyritic chondrules.

\section{Matrix}

The matrix is composed of phyllosilicates and of opaque aggregates, which petrographically resemble the poorly characterized ferro-oxy-sulphide phase (PCP) of the Murchison C2 chondrite (cf. Fuchs et al. 1973). The matrix also contains angular fragments of olivine, clinoenstatite and a few grains of Fe sulphides and carbonate. The phyllosilicates occur as grey, green and yellow phases (diameter up to $2.5 \mu \mathrm{m}$ ). The rinds surrounding the aggregates and chondrules are composed of the grey phyllosilicate and PCP. The chemical composition of the optically homogeneous rind material as determined by electron microprobe is given in Table 3 .

Bunch and Chang (1980) suggest that the phyllosilicates in the carbonaceous chondrites should be named according to their closest terrestrial analogues. Following this recommendation, the chemical composition (Table 3) and the optical properties of the matrix material were used in identification. Although the phyllosilicates in Kivesvaara are intimately intergrown with $\mathrm{PCP}$, it is safe to assume that $\mathrm{Si}, \mathrm{Mg}$ and $\mathrm{Al}$ are combined in phyllosilicate phases (cf. the PCP analyses in Fuchs et al. 1973; Bunch and Chang 1980). The concentration and the con- 
Table 3. Electron probe microanalyses (in weight percent) of matrix material in Kivesvaara and in nine other $\mathrm{C} 2$ chondrites.

\begin{tabular}{lcc}
\hline & Kivesvaara* & $\begin{array}{l}\text { Range in other } \\
\text { C2 chondrites }\end{array}$ \\
\hline $\mathrm{Na}_{2} \mathrm{O}$ & 0.35 & $0.07-1.14$ \\
$\mathrm{MgO}$ & 15.3 & $13.2-18.6$ \\
$\mathrm{Al}_{2} \mathrm{O}_{3}$ & 2.14 & $1.65-3.88$ \\
$\mathrm{SiO}_{2}$ & 25.2 & $20.4-26.9$ \\
$\mathrm{SO}_{3}$ & 5.35 & $4.31-8.53$ \\
$\mathrm{~K}_{2} \mathrm{O}$ & 0.06 & $0.04-0.13$ \\
$\mathrm{CaO}$ & 0.73 & $0.34-1.27$ \\
$\mathrm{TiO}_{2}$ & 0.09 & $0.04-0.10$ \\
$\mathrm{Cr}$ & 0.33 & $0.24-0.39$ \\
$\mathrm{MnO}_{3}$ & 0.20 & $0.15-0.19$ \\
$\mathrm{FeO}$ & 25.6 & $18.3-33.4$ \\
$\mathrm{NiO}$ & 2.62 & $1.45-2.05$ \\
\hline
\end{tabular}

* Mean of three analyses. Analyst: R. Törnroos, Geological Survey of Finland.

** Total iron as FeO.

Data on other C2 chondrites (Cold Bokkeveld, Crescent, Essebi, Haripura, Mighei, Murchison, Murray, Nogoya, Pollen) taken from McSween and Richardson (1977, p. 1146, Table 1).

centration ratios of these elements suggest that the phyllosilicate phases are serpentine (most probably antigorite). The $\mathrm{H}_{2} \mathrm{O}(+)$ content (9.66 wt.\%), if assumed to be confined to the phyllosilicate(s), and when normalized to the matrix volume $(77.5$ vol. $\%)$, gives the $\mathrm{H}_{2} \mathrm{O}(+)$ concentration as 14.8 wt.\%, likewise corresponding to the serpentine group.

\section{Clasts}

Monomineralic and polymineralic fragments are the most widespread clasts of the Kivesvaara meteorite (Table 2, Figs. 3 and 5). The monomineralic fragments are mainly composed of olivine $(94 \%)$ and of minor clinopyroxene with a grain size mode from 5 to $10 \mu \mathrm{m}$ (data from 115 grains). Polymineralic fragments are likewise mainly composed of olivine with minor clinopyroxene but with a grain size mode from 60 to $80 \mu \mathrm{m}$ (data from 37 grains). These grain size ranges suggest that the monomineralic fragments originated by crushing from the polymineralic aggregates, a fact that is also suggested by the general lack of rinds from around the monomineralic fragments. A few of the olivine-pyroxene fragments possess ovoidal surfaces, suggesting that they were formed by crushing of microporphyritic chondrules.

Optical examinations together with electron microprobe analyses show that most of the olivines are almost pure forsterite (composition mode at about $\mathrm{Fa}_{0.4}$ ), but the presence of more fayalitic compositions (up to about $\mathrm{Fa}_{23}$ ) was identified. The wide scatter of the olivine compositions shows that the Kivesvaara meteorite is unequilibrated. The grain sizes of olivine range from small matrix splinters up to euhedral crystals $1 \mathrm{~mm}$ in size. The pyroxene grains, both those in the coarse-grained aggregates and those occurring as individual grains, show a limited range of composition, being mainly the low-Ca pyroxene, clinoenstatite $\left(\mathrm{Fs}_{1.5}\right.$ and $\mathrm{FS}_{4.8}$ according to two electron microprobe analyses).

The fluid drop chondrules (Fig. 6) are composed of the following textural types: $52 \%$ metal-poor microporphyritic, $33 \%$ metal-rich microporphyritic, $6 \%$ excentroradial, $5 \%$ barred, and $4 \%$ relict glassy chondrules in the form of fibrous texture (data from 178 chondrules). These percentages are similar to the normal (H, L and LL) chondrites (cf. Gooding and Keil 1981). Chondrules are usually from 0.2 to $1.0 \mathrm{~mm}$ in diameter, but the largest chondrule as seen on the fracture surface is $2 \mathrm{~mm}$ in diameter. One unusual fluid drop chondrule with a tail was noted (Fig. 7).

The amoeboidal mineral aggregates are usually composed of fine-grained olivine. The length of these aggregates varies from 0.2 to $1.0 \mathrm{~mm}$. The presence of a few Ca-Al-Ti-rich aggregates (CAI inclusions) observed among these amoeboidal aggregates (Fig. 8) was verified by defocused beam electron microprobe runs. The CAI inclusions are characterized 


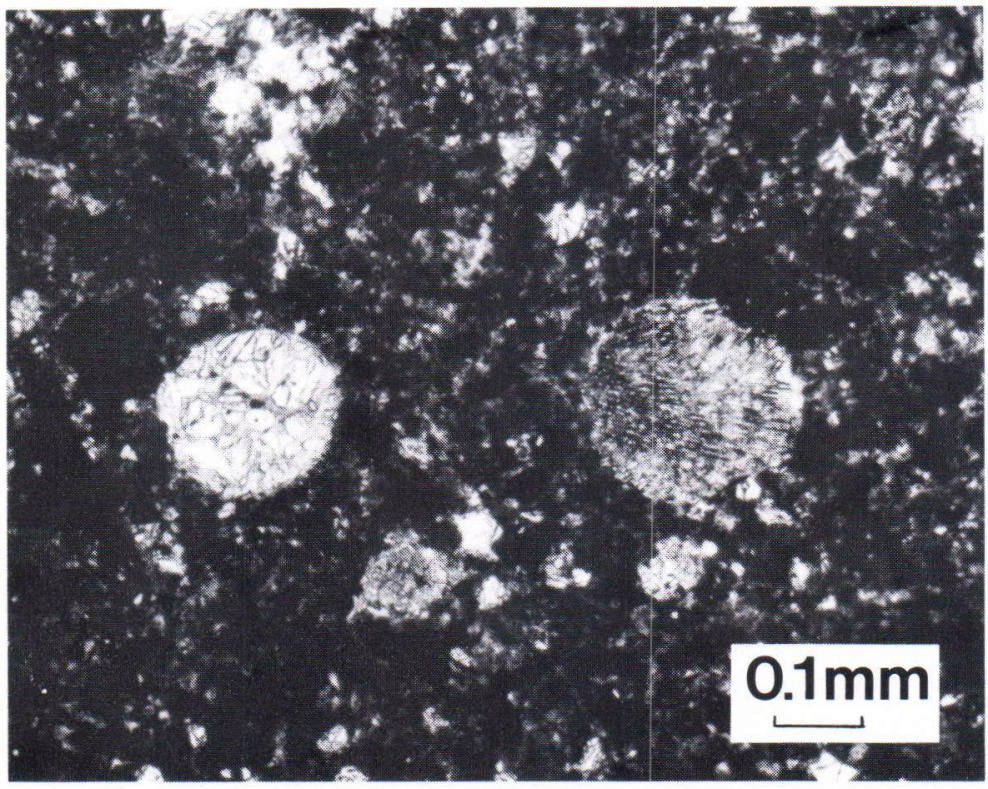

Fig. 6. Photomicrograph of the two main fluid drop chondrule types in the Kivesvaara meteorite: the larger is excentroradial and the smaller one microporphyritic. Transmitted, planepolarized light. by high-Ca pyroxenes and spinel-octahedra. Most of the fine-grained aggregates, including the CAI inclusions, are surrounded by a matrix rind. They are usually unbroken and with a zonal inner texture. This seems paradoxical: the coarse-grained aggregates (except the fluid drop chondrules) are almost always fragments, whereas these amoeboidal aggregates with their delicate and fragile outlines are unbroken. It is possible that the fragmental coarse-grained aggregates are xenolithic clasts, which may represent magmatic and/or metamorphic extra-terrestrial rock types (ureilite?).

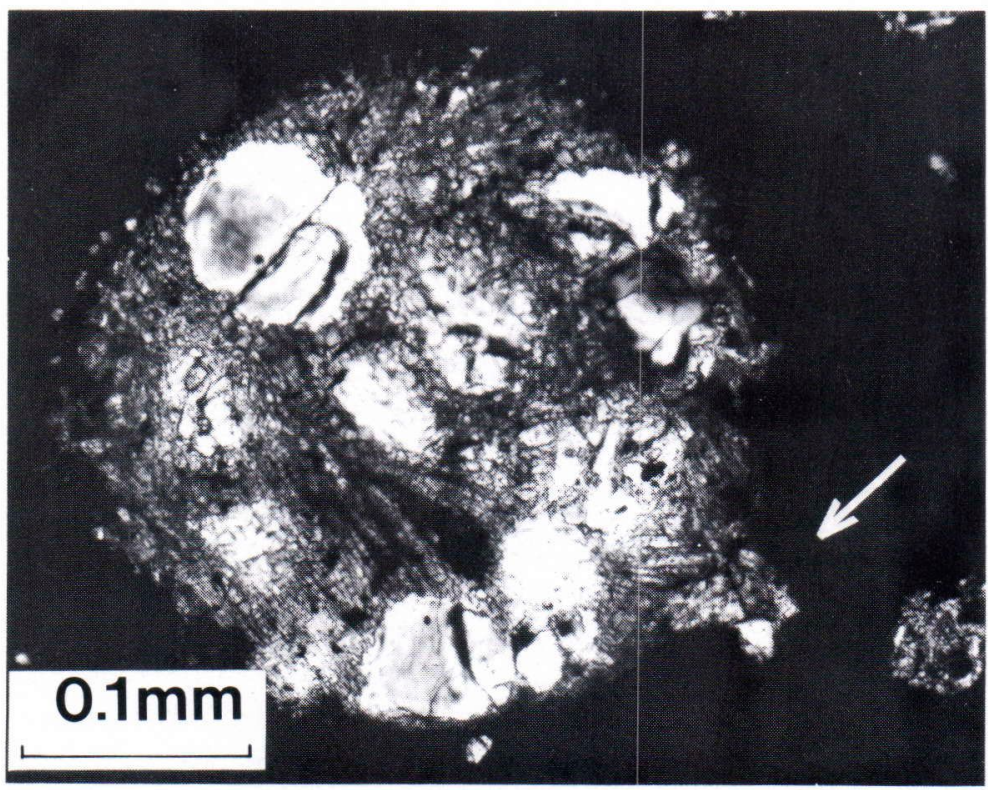

Fig. 7. Photomicrograph of a microporphyritic fluid drop chondrule with a tail (arrow). Transmitted light, crossed polarizers with mica plate. 


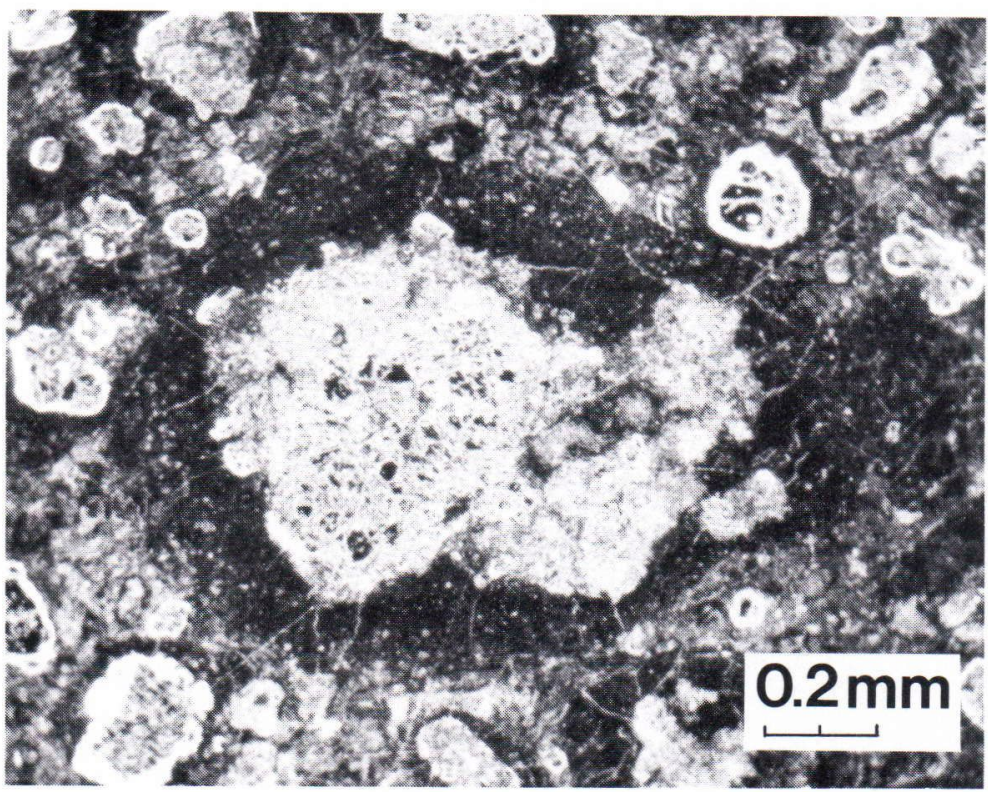

Fig. 8. Photomicrograph of a fine-grained $\mathrm{Ca}, \mathrm{Al}$-rich (CAI) inclusion. The dark rind smoothens the irregular outline of the CAI inclusion. Dark-field unpolarized, reflected light.

Although the Kivesvaara meteorite is brecciated (presence of black C1-like fragments), it lacks petrographic evidence of pervasive shock metamorphism. The few shock-deformed pyroxene and olivine grains and aggregates in the matrix material are lightly to moderately shocked according to the visual comparison scale of Carter et al. (1968). Note that the true fluid drop chondrules do not give any petrographic evidence of shock metamorphism.

Isolated grains of euhedral olivine and broken olivine fragments occur in the matrix (Fig. 9). Almost all the broken olivine frag-

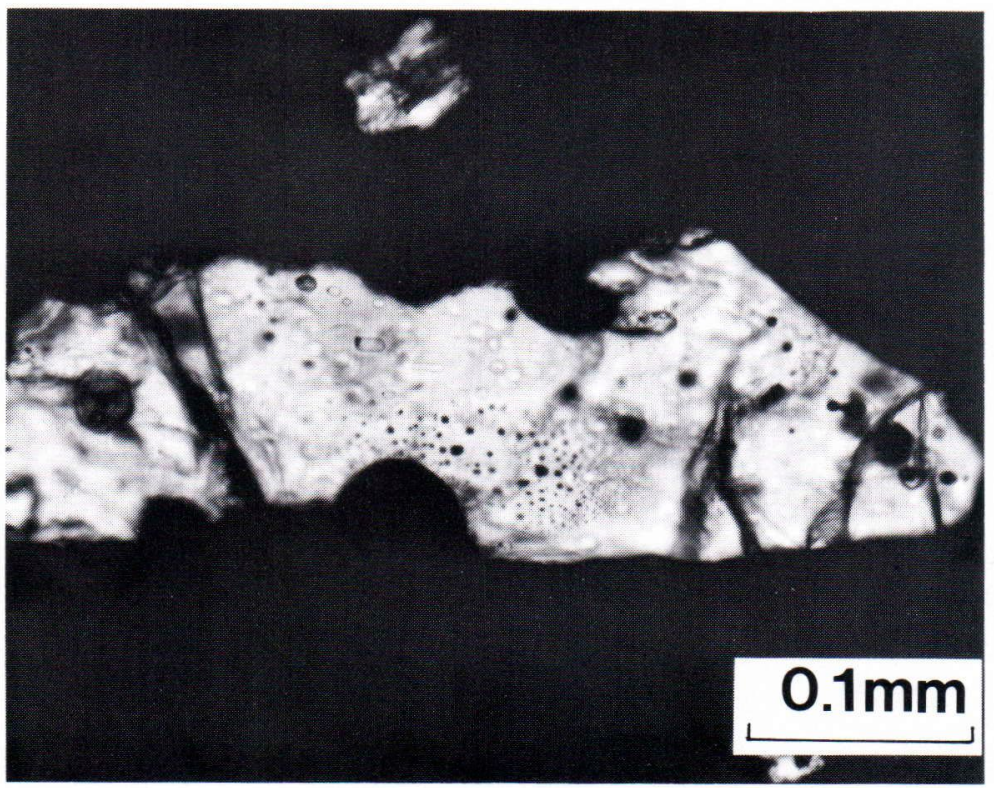

Fig. 9. Photomicrograph of an isolated olivine grain showing smooth crystal surfaces together with embayed margins. It contains glass and metallic nickel-iron inclusions. Transmitted, plane-polarized light. 


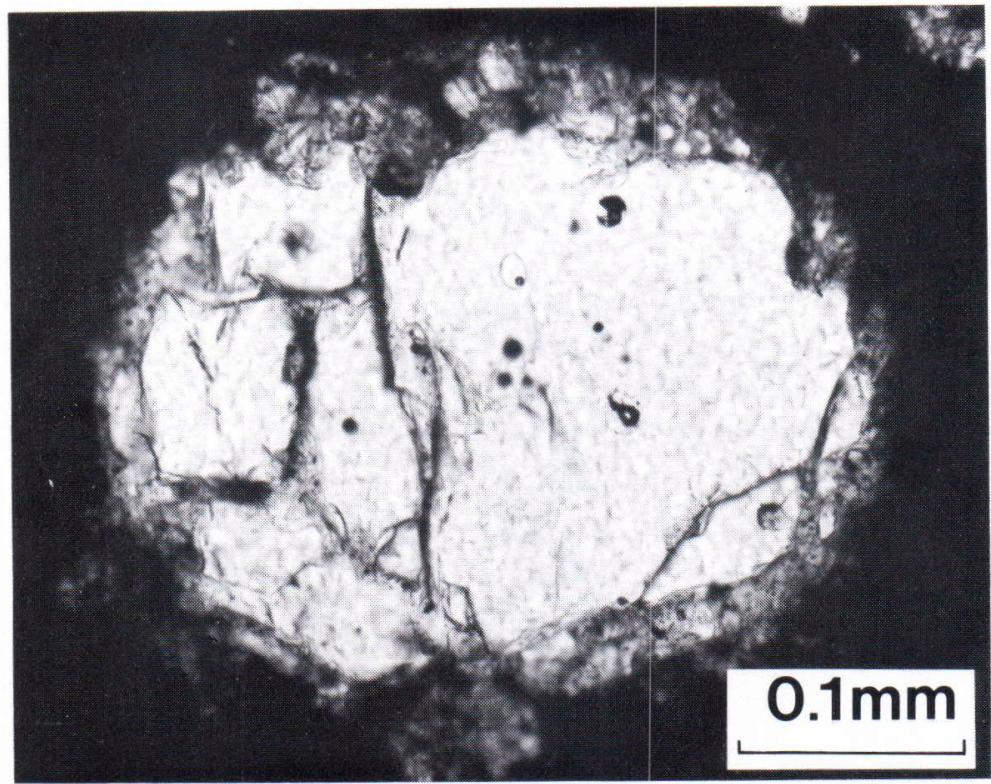

Fig. 10. Photomicrograph of an isolated olivine grain surrounded by fine-grained olivine. It contains primary (?) glass and metallic nickel-iron inclusions. Transmitted, planepolarized light.

ments show embayed margins, and some of them are surrounded by a narrow rim of microcrystalline olivine (Fig. 10), implying that they were once parts of crystal aggregates. The euhedral olivines, but not the broken olivine fragments, are usually surrounded by a matrix rind. This may indicate their different genesis: the euhedral olivines as condensates from a vapour as suggested by Olsen and Grossman (1978), and the broken olivine fragments from preformed crystals crystallized out of a liquid as suggested by Richardson and McSween (1978) and Roedder (1981).

The spherical melt and metal inclusions that occur in the olivine fragments (Figs. 9 and 10) are rare in the euhedral olivines. The most common diameter of the inclusions is about $5 \mu \mathrm{m}$. The phases observed are colourless isotropic glass, opaque spherules (all exposed are metallic nickel-iron), »vapour» bubble, octahedral opaque crystals (spinel?) and opaque fracture fillings (all exposed are iron sulphide). The most common phase combinations in individual inclusions are glass + »vapour» bubble and opaque spherules \pm glass. Anisotropic transparent phases were noted in recrystallized glass inclusions. The manifold phases can be explained by metastability phenomena (Roedder 1979). Metastability together with the cooling rate determines that the smallest glass inclusions are composed of glass exclusively and only the larger ones of »vapour» bubble and solid(s) together with glass.

Most of the glass and the metallic nickeliron inclusions in olivine are primary, because they occur as distinct inclusion zones or as isolated inclusions not connected with microfractures. The primary origin of most of the inclusions is further indicated by the few olivine grains containing inclusion-rich cores with inclusion-free rims and by the few opaque spherules surrounded by an inclusion-free halo. The primary origin of these inclusions is also indicated by the few elongated, tooth-like metallic nickel-iron and glass inclusions extending to the surface of the host crystals. The glass and metal inclusions in the Kivesvaara meteorite are petro- 
graphically similar to the inclusions observed in Murchison C2 (Fuchs et al. 1973; Roedder 1981) and in Murray C2 (Roedder 1979) chondrites.

\section{Chemistry}

\section{Methods}

Bulk chemical analysis was performed on the smaller meteorite fragment. About $5 \mathrm{~g}$ of the meteorite was crushed and ground after removing the outer and possibly contaminated parts of the sample. A few days later the powder showed a tendency to aggregate into pellets.

The weight loss at $105^{\circ} \mathrm{C}$ was measured on two $0.5 \mathrm{~g}$ subsamples, after which the material was fused with $\mathrm{Na}_{2} \mathrm{CO}_{3}$. $\mathrm{Si}$, Ca and $\mathrm{Mg}$ were determined gravimetrically, Fe and Ti colorimetrically and Al by AAS. Two $0.5 \mathrm{~g}$ subsamples were decomposed with $\mathrm{HF}-\mathrm{HNO}_{3}$ Aliquots of this solution were used to determine $\mathrm{Cr}, \mathrm{Ni}, \mathrm{Co}, \mathrm{Cu}$ and $\mathrm{Zn}$ by AAS. Two $0.25 \mathrm{~g}$ subsamples were decomposed with $\mathrm{HF}-\mathrm{HNO}_{3}-\mathrm{H}_{2} \mathrm{SO}_{4}$ and aliquots were taken to measure $\mathrm{Mn}$ and $\mathrm{P}$ colorimetrically and $\mathrm{Na}$ and $\mathrm{K}$ by AAS. Water was determined from a $0.100 \mathrm{~g}$ subsample by the Penfield method. One $0.100 \mathrm{~g}$ subsample was combusted in oxygen in which total S (elemental, sulfide, sulfate) was converted to sulphur dioxide. $\mathrm{SO}_{2}$ was titrated by the iodometric method. Total $\mathrm{C}$ was determined gravimetrically by weighing the $\mathrm{CO}_{2}$ produced by the combustion of one $0.200 \mathrm{~g}$ subsample in oxygen. This method is based on the oxidation of carbonaceous material and the decomposition of carbonates to carbon dioxide. Ga was determined spectrographically. We were not able to identify and determine the small amount of organic compounds that always occurs in carbonaceous chondrites because Geological Survey of Finland is not equipped for research of that kind.
Results

The chemical composition of the Kivesvaara meteorite is given in Table 4 in the form of oxides and of troilite. Metallic iron was not determined, because our petrographic observations showed that it only forms inclusions in olivine with neglible volume amounts. The convention of presenting sulphur as FeS, however, is not valid for the Kivesvaara meteorite, because, according to the modal analysis, the iron sulphide content is considerably smaller than the content calculated on the basis of the total sulphur content. Sulphur mainly occurs in the matrix material as the poorly characterized ferro-oxy-sulphide phase (PCP) and probably as sulphates. When the bulk chemical analysis (Table 4) is compared to the electron probe microanalysis of the matrix material (Table 3 ) recalculated to $88 \%\left(\mathrm{H}_{2} \mathrm{O}\right.$ about $\left.12 \%\right)$, it is observed that $\mathrm{Fe}$ and $\mathrm{Ni}$ are enriched in the matrix material and $\mathrm{Ca}$ and $\mathrm{Al}$ in the clasts. The elemental composition of the Kivesvaara meteorite is given in Table 5 .

\section{Classification and discussion}

The carbonaceous chondrites were first grouped into types I, II and III by Wiik (1956). His classification, based on their carbon, water and sulphur contents, is now widely accepted with a few semantic rather than scientific changes (Table 6). Type I and Type II of Wiik (1956) correspond exactly to the more recent $\mathrm{C} 1$ and $\mathrm{C} 2$ groups, but Wiik's type III has been divided on the basis of major element ratios and petrography into groups CO (Ornans type) and CV (Vigarano type) (see Van Schmus and Hayes 1974). It must be stressed that the Van Schmus and Wood (1967) grouping is petrographic, whereas the Wiik (1956) and Wasson (1974) groupings are chemical. The interesting point is that they both give consistent results. The 
Table 4. Bulk chemical analyses of the Pollen, Murchison and Kivesvaara C2 chondrites (in weight percent).

\begin{tabular}{|c|c|c|c|}
\hline Component & $\begin{array}{l}\text { Pollen } \\
\text { (1) }\end{array}$ & $\begin{array}{l}\text { Murchison } \\
\text { (2) }\end{array}$ & $\begin{array}{l}\text { Kivesvaara } \\
\text { (3) }\end{array}$ \\
\hline $\mathrm{Fe}^{\circ}$ & 0.1 & 0.13 & n.d.* \\
\hline $\mathrm{SiO}_{2}$ & 27.92 & 29.07 & 29.39 \\
\hline $\mathrm{MgO}$ & 19.55 & 19.94 & 20.56 \\
\hline $\mathrm{FeO}$ & 20.67 & 22.39 & 20.03 \\
\hline $\mathrm{Al}_{2} \mathrm{O}_{3}$ & 2.83 & 2.15 & 2.50 \\
\hline $\mathrm{CaO}$ & 1.86 & 1.89 & 1.94 \\
\hline $\mathrm{Na}_{2} \mathrm{O}$ & 0.63 & 0.24 & 0.35 \\
\hline $\mathrm{K}_{2} \mathrm{O}$ & 0.30 & 0.04 & 0.06 \\
\hline $\mathrm{Cr}_{2} \mathrm{O}_{3}$ & 0.45 & 0.48 & 0.45 \\
\hline $\mathrm{MnO}$ & 0.216 & 0.20 & 0.23 \\
\hline $\mathrm{TiO}_{2}$ & 0.14 & 0.13 & 0.12 \\
\hline $\mathrm{P}_{2} \mathrm{O}_{5}$ & 0.3 .0 & 0.23 & 0.38 \\
\hline $\mathrm{NiO}$ & 1.72 & 1.75 & 1.49 \\
\hline $\mathrm{CoO}$ & 0.08 & 0.08 & 0.07 \\
\hline $\mathrm{CuO}$ & n.d. & n.d. & 0.02 \\
\hline $\mathrm{ZnO}$ & n.d. & n.d. & 0.02 \\
\hline $\mathrm{FeS}$ & 8.14 & 7.24 & 8.23 \\
\hline $\mathrm{H}_{2} \mathrm{O}(+)$ & 12.95 & 8.95 & 9.66 \\
\hline $\mathrm{H}_{2} \mathrm{O}(-)$ & 0.62 & 1.14 & 1.90 \\
\hline $\mathrm{SO}_{3}$ & n.d. & 0.90 & n.d. \\
\hline $\mathrm{C}$ & 1.65 & 1.85 & 2.20 \\
\hline $\mathrm{CO}_{2}$ & n.d. & 1.00 & n.d. \\
\hline Total & 100.13 & 99.80 & 99.60 \\
\hline Total Fe & 21.29 & 22.13 & 20.75 \\
\hline
\end{tabular}

* n.d., not determined, see text.

Analysts: (1) H. B. Wiik, (2) E. Jarosewich (1971), (3) R. Saikkonen.

real problem in terminology arises from the lack of chondrules in the $\mathrm{C} 1$ chondrites. These stones, however, are chemically and petrographically similar to the matrix of the C2 chondrites.

The chemical, mineralogical and textural features of the Kivesvaara meteorite are typical of C2 chondrites. The bulk carbon, water and sulphur contents are consistent with the type II carbonaceous chondrites in the Wiik (1956) classification. The $\mathrm{Si} / \mathrm{Mg}$ ratio is lower in Kivesvaara than in other chondrite types; this, too, is consistent with carbonaceous chondrites (cf. Van Schmus and Wood 1967). The chemical composition of the Kivesvaara
Table 5. Elemental composition of the Kivesvaara C2 chondrite (in weight percent).

\begin{tabular}{lc}
\hline $\mathrm{H}^{*}$ & 1.08 \\
$\mathrm{C}$ & 2.20 \\
$\mathrm{Na}$ & 0.26 \\
$\mathrm{Mg}$ & 12.40 \\
$\mathrm{Al}$ & 1.32 \\
$\mathrm{Si}$ & 13.73 \\
$\mathrm{P}$ & 0.17 \\
$\mathrm{~S}$ & 3.00 \\
$\mathrm{~K}$ & 0.050 \\
$\mathrm{Ca}$ & 1.38 \\
$\mathrm{Ti}$ & 0.072 \\
$\mathrm{Cr}$ & 0.31 \\
$\mathrm{Mn}$ & 0.18 \\
$\mathrm{Fe}$ & 20.75 \\
$\mathrm{Co}$ & 0.058 \\
$\mathrm{Ni}$ & 1.17 \\
$\mathrm{Cu}$ & 0.012 \\
$\mathrm{Zn}$ & 0.019 \\
$\mathrm{Ga}$ & 0.0006 \\
\hline \multirow{2}{*}{ calculated from $\mathrm{H}_{2} \mathrm{O}(+)$}
\end{tabular}

matrix (Table 3) falls within the range reported for C2 matrix material by McSween and Richardson (1977).

The petrographic criteria for grouping the Kivesvaara meteorite into the carbonaceous chondrites of the petrological type 2 in the Van Schmus and Wood (1967) classification are 1) the presence of sharply outlined fluid drop chondrules and of phyllosilicate matrix material of opaque appearance, 2) the unequilibrated olivine compositions, 3) pyroxene occurring as clinoenstatite, 4) the absence of feldspar, and 5) the presence of glass only as inclusions embedded in olivines. McSween (1979) has suggested that the C2s may possibly be arranged in a metamorphic series in which their matrix volume increases with the increasing grade of metamorphism. According to its matrix volume percentage, the $\mathrm{Ki}$ vesvaara meteorite is situated towards the more metamorphosed end of this series. The grain size frequency distribution in Kivesvaara falls between the ranges of the $\mathrm{C} 2$ and C3(0) types (Fig. 4), which, together with the chem- 


\begin{tabular}{|c|c|c|c|c|}
\hline $\begin{array}{l}\text { Wiik } \\
\text { (1956) }\end{array}$ & $\begin{array}{l}\text { Van Schmus } \\
\text { and } \\
\text { Wood (1967) }\end{array}$ & $\begin{array}{l}\text { Wasson } \\
(1974)\end{array}$ & $\begin{array}{l}\text { Sears } \\
(1978)\end{array}$ & $\begin{array}{l}\text { Type } \\
\text { meteorite }\end{array}$ \\
\hline Type I & $\mathrm{C} 1$ & CI & $\mathrm{C} 1$ & Ivuna \\
\hline Type II & $\mathrm{C} 2$ & $\mathrm{CM}$ & $\mathrm{C} 2$ & Mighei \\
\hline \multirow[t]{2}{*}{ Type III } & $\mathrm{C} 3$ & $\mathrm{CO}$ & $\mathrm{CO}$ & Ornans \\
\hline & & $\mathrm{CV}$ & $\mathrm{CV}$ & Vigarano \\
\hline
\end{tabular}

Table 6. Nomenclature of the main groups (more than one specimen) of the carbonaceous chondrite class. ical parameters of Kallemeyn and Wasson (1981), places it in the suggested C2-C3(0) clan of the carbonaceous chondrites.

The bulk chemical composition of Kivesvaara is very close to Murchison C2 chondrite (Table 4). Despite the similarity in their chemical composition, these two meteorites show petrographical differences (Fig. 1 in this paper; Fig. 1 in Fuchs et al. 1973). Accordingly, the grain-size frequency distribution for the Murchison C2 chondrite (King and King 1978) shows more coarse-grained material than that for Kivesvaara (Fig. 4).

Like the other $\mathrm{C} 2$ meteorites, the Kivesvaara meteorite is composed of manifold clasts embedded in matrix material. The most common clast types are olivine and pyroxene fragments and microporphyritic chondrules. They are probably fragments of rocks representing deeper levels in the parent body. The true fluid drop chondrules are unshocked and rare in Kivesvaara. Their textural types are similar to the types found in the ordinary chondrites. This indicates a common source of the chondrules in chondrites. The matrix rinds surround the chondrules, aggregates and euhedral olivines but not the mineral fragments.

The matrix material of the Kivesvaara C2 meteorite contains relicts of altered clasts. This texture suggests that the C2s in general (note the similar chemical composition between Kivesvaara and the other C2s) are composed of three phases: 1) the oldest clast phase now preserved as relicts in the matrix material, 2) the normal matrix material, and 3) the high-temperature unaltered clasts. Possible explanations for the genesis of these matrix clasts are alteration of older clasts (thermal or aquotical) or primary origin as dust aggregates.

Acknowledgements. We thank Messrs. Pertti Huusko and Esko Leinonen from Paltamo for generously donating their specimens of the Kivesvaara meteorite for scientific purposes and Professor Birger Wiik, former Head of the Chemistry Department in the Geological Survey of Finland, for the loan of samples of the Allende C3(V) chondrite for reference and for allowing us to publish his chemical analysis of the Pollen C2 chondrite. We are grateful to Professor Wiik, Dr. Martti Lehtinen, University of Helsinki, and to Mr. Lauri J. Pesonen, Ph. D., Mr. Ilmo T. Kukkonen, Dipl. Eng., and Mr. Kristian Lindqvist, M. Sc., from the Geological Survey of Finland for their helpful criticism of the manuscript. We also wish to thank the staff members of the Geological Survey of Finland; Miss Ringa Danielsson, M. Sc., Mr. Raimo Lahtinen, B. Sc., and Mrs. Mervi Wiik, B. Sc., assisted in the chemical analysis, Dr. Ragnar Törnroos pertormed the microprobe analyses, and Messrs. Toivo Alanen, Risto Lanki and Jouko Pääkkönen prepared the thin and polished sections. Mrs. Gillian Häkli, B. A., corrected the English text. 


\section{References}

Alfvén, H. \& Arrhenius, G., 1976. Evolution of the Solar System. NASA SP-345, Washington, D. C., 599 p.

Allen, J. S., Nozette, S. \& Wilkening, L. L., 1980. A study of chondrule rims and chondrule irradiation records in unequilibrated ordinary chondrites. Geochim. Cosmochim. Acta 44, 11611175.

Bunch, T. E. \& Chang, S., 1980. Carbonaceous chondrites - II. Carbonaceous chondrite phyllosilicates and light element geochemistry as indicators of parent body processes and surface conditions. Geochim. Cosmochim. Acta 44, $1543-1577$.

Carter, N., Raleigh, C. \& de Carli, P., 1968. Deformation of olivine in stony meteorites. J. Geophys. Res. 73, 5439-5461.

Desnoyers, C., 1980. The Niger (I) carbonaceous chondrite and implications for the origin of aggregates and isolated olivine grains in C2 chondrites. Earth Planet. Sci. Lett. 47, 223-234.

Dodd, R. T., 1981. Meteorites. A Petrologic-Chemical Synthesis. Cambridge University Press, Cambridge, $368 \mathrm{p}$.

Fuchs, L. H., Olsen, E. \& Jensen, K. J., 1973. Mineralogy, mineral-chemistry, and composition of the Murchison (C2) meteorite. Smiths. Contrib. Earth Sci., Number 10, 39 p.

Gooding, J. L. \& Keil, K., 1981. Relative abundances of chondrule primary textural types in ordinary chondrites and their bearing on conditions of chondrule formation. Meteoritics 16, $17-43$.

Jarosewich, E., 1971. Chemical analysis of the Murchison meteorite. Meteoritics 6, 49-52.

Kallemeyn, G. W. \& Wasson, J. T., 1981. The compositional classification of chondrites - I. The carbonaceous chondrite groups. Geochim. Cosmochim. Acta 45, 1217-1230.

King, E. A., Carman, M. F. \& Butler, J. C., 1972. Chondrules in Apollo 14 samples: Implications for the origin of chondritic meteorites. Science $175,59-60$.

King, T. V. V.\& King, E. A., 1978. Grain size and petrography of C2 and C3 carbonaceous chondrites. Meteoritics 13, 47-72.

Krinsley, D. \& Leach, R., 1981. Properties of electrostatic aggregates and their possible presence on Mars. Precambrian Res. 14, 167-178.

Kurat, G. \& Kracher, A., 1975. Preliminary report on the Cochabamba carbonaceous chondrite (abs). Meteoritics 10, 432-433.

Macdougall, J. D. \& Kothari, B. K., 1976. Formation chronology for C2 meteorites. Earth Planet. Sci. Lett. 33, 36-44.

Mason, B., 1971. The carbonaceous chondrites - A selective review. Meteoritics 6, 59-70.

McKay, D. S., Greenwood, W. D. \& Morrison, D. A., 1970. Morphology and related chemistry of small lunar particles from Tranquility Base. Science 167, 654-656.

McSween, H. Y., Jr., 1979. Alteration in CM carbonaceous chondrites inferred from modal and chemical variations in matrix. Geochim. Cosmochim. Acta 43, 1761-1770.

McSween, H. Y., Jr. \& Richardson, S. M., 1977. The composition of carbonaceous chondrite matrix. Geochim. Cosmochim. Acta 41, 1145-1161.

Moore, C. B., 1982. Overview of Antarctic carbonaceous chondrites. In Marvin, U. B. and Mason, B. (eds.) Catalog of meteorites from Victoria Land, Antarctica, 1978-1980. Smiths. Contrib. Earth Sci., Number 24, pp. 65-66.

Nagy, B., 1975. Carbonaceous Meteorites. Elsevier, Amsterdam, 747 p.

Olsen, E. \& Grossman, L., 1978. On the origin of isolated olivine grains in Type 2 carbonaceous chondrites. Earth Planet. Sci. Lett. 41, 111-127.

Richardson, S. M. \& McSween, H. Y., Jr., 1978. Textural evidence bearing on the origin of isolated olivine crystals in C2 carbonaceous chondrites. Earth Planet. Sci. Lett. 37, 485-491.

Roedder, E., 1979. Origin and significance of magmatic inclusions. Bull. Minéral. 102, 487-510.

Roedder, E., 1981. Significance of Ca-Al-rich silicate melt inclusions in olivine crystals from the Murchison type II carbonaceous chondrite. Bull. Minéral. 104, 339-353.

Scott, E. R. D., 1982. Isotopic anomalies in meteorites. Nature 297, 361-362.

Sears, D. W., 1978. The Nature and Origin of Meteorites. Monographs on Astronomical Subjects: 5 . Adam Hilger Ltd, Bristol, 187 p.

Smith, J. V., 1982. Heterogenous growth of meteorites and planets, especially the Earth and Moon. J. Geol. 90, 1-48.

Wasson, J. T., 1974. Meteorites. Classification and Properties. Springer, Berlin, 316 p.

Wiik, H. B., 1956. The chemical composition of some stony meteorites. Geochim. Cosmochim. Acta 9, 279-289. 
Van Schmus, W. R. \& Hayes, J. M., 1974. Chemical and petrographic correlations among carbonaceous chondrites. Geochim. Cosmochim. Acta $38,47-64$.

Van Schmus, W. R. \& Wood, J.A., 1967. A chemical- Manuscript received, November 24, 1982 petrologic classification for the chondritic meteorites. Geochim. Cosmochim. Acta 31, 747765 . 